\title{
TENDENCIA ACTUAL, SOBRE LAS REGLAS DE INTERPRETACIÓN \\ EN LAS REFORMAS DEL CÓDIGO PENAL, REFERENTES \\ AL DELITO DE TERRORISMO, DESDE LA ÓPTICA DE LA “APOLOGÍA DEL ODIO”
}

\author{
Abogda. Jenny Mabel Díaz ${ }^{1}$ \\ Carlos Francisco Padilla Díaz ${ }^{2}$
}

\section{RESUMEN}

La investigación aborda los temas y artículos de reformas penales en la actualidad, lo cual sustentan y fundamentan las diversas maneras de interpretación de la regla en la actualidad en la apología del odio, dentro de la praxis diaria del pueblo hondureño, con el fin de esclarecer lo que significa esa dicha apología en Honduras.

PALABRAS CLAVE: Interpretación, terrorismo, delito, artículo, apología, penal, reformas

\section{ABSTRACT}

The investigation deals with the themes and articles of penal reforms at present, which support and support the different ways of interpreting the rule currently in the apology of hate, within the daily praxis of the Honduran people, in order to Clarify what that said apology means in Honduras.

KEYWORDS: Interpretation, terrorism, crime, article, apology, criminal, reforms.

Fecha de Recepción: 25 de mayo del 2017

Fecha de Aceptación: 05 de octubre del 2017

\footnotetext{
1 Abogada, graduada de la UNAH Universidad Nacional Autónoma de Honduras, Especialista en Derecho Mercantil, Juez de Paz, Corte Suprema de Justicia. E-mail: jmdiaz@poderjudicial.gob.hn

2 Estudiante de Derecho de la Facultad de Ciencias Jurídicas en la UNAH Universidad Nacional Autónoma de Honduras.

E-mail: car.padilla13@yahoo.com
} 


\section{INTRODUCCIÓN}

$\mathrm{E}$ presente artículo contribuye a la argumentación de las nuevas reformas en el código penal hondureño, lo cual fue publicado por el diario oficial la gaceta No. 34,276, del día 27 de Febrero del 2017, por lo cual se contribuirá a despejar el termino de apología del odio/ terrorismo, que está estipulado en el artículo 335 en el cual se despliegan dos incisos que es el A y B, dentro del mismo documento.

Los objetivos que persigue esta investigación es alcanzar un alto grado de interpretación referente al tema de la apología del odio y el terrorismo en Honduras, explicando y sintetizando lo referente al tema, y dejando en claro en qué casos se le llamará apología. Así mismo obtener el mayor conocimiento posible como podremos identificar el terrorismo, actualizándonos acerca de nuevo código y el actual código que son los que están en discusión.

Se presentaran las siguientes interrogantes: ¿Iré arrestado por estar en contra del gobierno?, ¿Soy terrorista si salgo a las calles?, ¿Odio el gobierno actual?, entre muchas interrogantes más.

\section{METOdOLOGÍA}

Para la presente investigación, el artículo que se interpreta La apología del odio se base en el método cualitativo lo cual es un método científico empleado en diferentes disciplinas, especialmente en las ciencias sociales. La investigación cualitativa busca adquirir información en profundidad para poder comprender el comportamiento humano y las razones que gobiernan tal comportamiento.

En la presente investigación investigamos los ¿por qué? y los ¿cómo?, no sólo los ¿qué? ¿Dónde? y ¿cuándo? Por esto mismo, en el método cualitativo se utilizan muestras pequeñas, más enfocadas a un tema en particular.

La metodología usada en este artículo se basó en investigaciones del código penal vigente, la reforma que hubo el 27 de Febrero del artículo 335 del mismo código, y el nuevo proyecto del código penal el que actualmente se está discutiendo para su aprobación, en el cual se añaden algunos comentarios de algunos congresistas debido a que fue un tema que afecto grandemente a la población.

Y Además en otros artículos que hablan acerca del terrorismo, agregando comentarios de diferentes puntos de vista de otros autores.

Durante la investigación utilizando el método cualitativo el cual se produce información sólo en los casos particulares que estudia, por lo que es difícil generalizar, sólo se puede hacer mediante hipótesis. Es mediante el método cuantitativo que esas hipótesis pueden ser verificadas valiéndose del método empírico.

Las hipótesis fueron creadas desde muchos puntos de vista, debido a que el pueblo saco las sus conclusiones y se presentaron daños a la propiedad y muchos congresistas también hicieron que el problema se hiciera más grande.

Basados en principios teóricos como la fenome-nología, el impacto social que está causando, la hermenéutica, la interacción social utilizando métodos de recolección de la información que difieren del 
método cuantitativo al no poder ser plasmados en números, pero si en información y textos legales. La idea es explorar las relaciones sociales y describir la realidad tal como la experimentan los protagonistas.

Los materiales utilizados en estas investigacio-nes son confiables debido a que es un tema en el cual la población debe estar enterada, por el cual en los tribunales nadie puede alegar desconoci-miento de la ley, debido a que este tema que se está tratando es un delito que se comete a diario en muchos medios de comunicación masivo.

En este método también se utilizó lo que es el método cuantitativo en el caso que se le realizo una serie de preguntas a un abogado penalista del departamento de derecho penal, de la facultad de ciencias jurídicas de la UNAH.

El método cuantitativo también se conoce como investigación cuantitativa, empíricoanalítico, racionalista o positivista es aquel que se basa en los números para investigar, analizar y comprobar información y datos; este intenta especificar y delimitar la asociación o correlación, además de la fuerza de las variables, la generalización y objetivación de cada uno de los resultados obtenidos.

Para deducir una población; y para esto se nece-sita una recaudación o acopio metódico u orde-nado, y analizar toda la información numérica que se tiene.

Este método es uno de los más utilizados por la ciencia, la informática, la matemática y como herramienta principal las estadísticas. Es decir que los métodos cuantitativos utilizan valores cuantificables como porcentajes, magnitudes, tasas, costos entre muchos otros; entonces se puede declarar que las investigaciones cuantitativas, realizan preguntas netamente específicas y las respuestas de cada uno de los participantes plasmadas en las encuestas, obtienen muestras numéricas.

Realizando las siguientes preguntas:

1. ¿Qué piensa usted de la actual reforma penal al artículo 335? Lo cual él respondió de la siguiente manera: Todo se por mejorar la crisis de falta de justicia en el país, en el cual él dijo que consideraba la reforma como algo de asuntos políticos, para poder reprimir el pueblo.

2. ¿Cree que es justa esa decisión de los congresistas para el pueblo Hondureño?, respondió: La ley busca la justicia y la equidad e igualdad, y la decisión fue aprobada con la cuarta parte de los con-gresistas debido a la ausencia de una bancada en reunión ordinaria ya antes convocada.

3. ¿Considera que la Apología del Odio se tiene considerar terrorismo? En si no se tiene que considerar como terrorismo aunque van ligados ambos tér-minos porque debido a que uno depende el otro, pero siempre se pueden tomar como terrorismo que es lo que hacen otros países.

4. ¿Según usted con sus años de experiencia el terrorismo en otros ámbitos es malo? Respondió: El terrorismo siempre ha existido, y es difícil poder radicarlo, debido a que se practica de diferentes maneras. Que se han desarrollado en múltiples formas y en distintos campos de desarrollo.

5. ¿Considera que esa reforma detendrá a muchas personas que denigran y crean apología por medios de comunicación? Respondió: Que si debido que eso se es-taba volviendo muy común, y hasta era normal en la población hondureña, debido a que casi en todos los días se observaba en el mundo del periodismo denigración a ciertas personas y personajes de la audiencia pública. 
En el cual es abogado expreso que la reforma penal este o no a favor del pueblo se tiene que cumplir, debido a que la apología del odio no se debería considerar como terrorismo si no como falta u otro tipo de sanción, en el cual esto tiene algún sentido político por la falta de muchos congresistas el día que se aprobó la reforma.

\section{ANTECEDENTES}

Según el artículo 335 de nuestro código penal publicado en el diario oficial la Gaceta No. 24,264 de fecha de 12 de Marzo de 1984, y vigente a partir de 12 de marzo de 1985, es tipificado por lo cual consta de preceptos y estipula que los tratados o instrumentos ratificados por Honduras, respecto al terrorismo, dentro los cuales menciona 10 convenios.

Y dentro del mismo menciona la pena que es reclusión y multa, claro está que esto es si cumple los requisitos según el artículo y los convenios. En el año 2016 y 2017 el soberano Congreso Nacional de Honduras (CN), implemento El nuevo Proyecto del Código Penal con modificaciones y reformas en muchos ámbitos del área penal, según el proyecto los artículos estipulados en el Capítulo VI, en los artículos 586 al artículo 595, estipulan muchas más normas y requisitos para poder ser enjuiciados con el delito de terrorismo. Durante el día viernes 24 de febrero del 2017, el pleno y sus congresistas aprobaron la reforma del artículo 335 de nuestro actual código, lo cual causo muchas críticas dentro del pueblo hondureños, por lo cual se expandió más lo que es el precepto y la pena a cumplir.

Por lo que dichos incisos muestran una serie de formas y requisitos para lo que ahora se llamara como terrorismo. El 27 de Febrero del año en curso entra en vigencia el actual artículo antes mencionado, para ya poder ir enjuiciando a las personas que se consideren que hayan cometido esa falta.

\section{ANALISÍS DEL CÓDIGO, SUS REFORMAS Y ADICIONES}

Según el artículo 335 de nuestro actual código penal el cual ya fue derogado el 27 de febrero del año en curso, hablaba que era considerado terrorista aquella persona que realizara cualquier acto destinado a causar muerte o lesiones corporales graves a un ciudadano civil o a cualquier otra persona, en este artículo nos expresa que el terrorismo.

Forma violenta de lucha política, mediante la cual se persigue la destrucción del orden establecido o la creación de un clima de terror e inseguridad susceptible de intimidar a los adversarios o a la población en general, donde el terrorismo lo practican Las formas y herramientas para combatir a las personas y organizaciones a las que un estado califica de terroristas o potencialmente terroristas, han sido y son objeto de discusión.

En algunos casos se ha sostenido que la represión del terrorismo debe realizarse siguiendo los procedimientos legales, respetando los derechos humanos de las personas y preservando el sistema democrático, pero en otros casos el Estado ha recurrido a procedimientos ilegales, fuerzas parapoliciales y paramilitares, autorización de la tortura, suspensión de los derechos humanos e incluso instalación de dictaduras.

Entre los procedimientos para reprimir el terrorismo, también se ha sostenido la necesidad de secuestrar y suprimir la identidad de los hijos de las personas a los que el Estado imputa ser te-rroristas. (Código Penal “Decreto 144-83", 1984). 


\title{
Según el nuevo Proyecto que entra a discusión en el congreso Nacional.
}

\author{
Capítulo VI Terrorismo
}

\section{Articulo 586 Asociación terrorista.}

1. Se consideran asociaciones terroristas las constituidas, sea de modo permanente o transitorio, por dos (2) o más personas, para cometer algún delito, con alguna de las finalidades siguientes:

a. Subvertir gravemente el orden constitucional;

b. Alterar gravemente la paz pública; o

c. Provocar un estado de terror en la población o parte de ella.

Comentario: En este capítulo el nuevo proyecto habla y especifica muchos artículos y distintos requisitos de lo que será el nuevo código penal, lo cual juzgara como terrorista a las personas que hayan cometido ese hecho y pondrá una pena en la cual el juez decidirá, si pone la sanción, multas y reclusión en la cual se pueden aplicar cualquiera de las mismas, o las tres formas al mismo tiempo.

Depende la gravedad del asunto, Tienen también la consideración de asociaciones terroristas las que, aun teniendo como objeto constitutivo un lícito, realicen en todo o en parte las conductas a las que se refiere.

Los directivos, promotores y financistas de la asociación deben ser castigados con las penas de prisión de siete (7) a quince (15) años y multa de mil (1000) a dos mil (2000) días. Los simples integrantes de la asociación terrorista deben ser castigados con las penas de prisión de cinco (5) a siete (7) años y multa de quinientos (500) a mil (1000) días.

Comentario: En las cuales las penas tienen que ser impuestas si el imputado cumple todos los requisitos formales por el mismo código.

Estas penas se deben imponer con independencia de las que correspondan por los concretos actos delictivos realizados por los integrantes de la asociación terrorista, llevados a cabo con las finalidades mencionadas en el numeral primero de este artículo.

Quien, fuera de los casos contemplados en los artículos del capítulo de terrorismo, colabora con una asociación terrorista proporcionando información sobre personas, hechos, bienes o insta-laciones, poniendo a disposición de la asociación o de sus integrantes muebles o inmuebles, facili-tando el traslado, acogimiento u ocultamiento de personas o todo tipo de materiales pertenecientes.

Relacionados o con destino a la asociación, o prestándole servicios tecnológicos de cualquier tipo, debe ser castigado con las penas de prisión de tres (3) a cinco (5) años y multa de quinientos (500) a mil (1000) días, a no ser que por su parti-cipación en un concreto delito merezca mayor sanción.

Las penas son más explicitas y se elimina cualquier tipo de ley especial en la cual no remite a ninguna ley, porque en su mayoría se explican en el proyecto. 
En el Proyecto se contemplan los siguientes delitos:

1. Articulo 586 Asociación terrorista.

2. Articulo 587 Colaboración sin pertenencia.

3. Articulo 588 Agravación de las penas en los delitos en particular.

4. Articulo 589 Atenuantes específicas.

5. Articulo 590 Asistencia a campos de entrenamiento.

6. Articulo 591 Ciberterrorismo o terrorismo electrónico.

7. Articulo 592 Punición de actos preparatorios.

Todos los delitos graves cometidos con finalidad terrorista tienen la consideración de de-litos de terrorismo a efectos del presente Capítulo, y deben ser castigados con la pena superior en un tercio (1/3) a la prevista en el correspondiente precepto. Si se trata de delitos de tenencia, porte o depósito de armas o explosivos, la pena se incrementará en dos tercios $(2 / 3)$.

Se podrá disminuir la pena por asociación terrorista hasta en un tercio (1/3) si el integrante de la misma:

1. Confiesa las actividades delictivas en las que haya participado y realiza, directa o indirectamente, la consecuente aportación de pruebas;

2. Colabora con las autoridades para prevenir la realización de delitos terroristas o atenuar sus efectos, o para aportar u obtener pruebas de otros ya cometidos;

3. Colabora con las autoridades para la identificación, persecución y procesamiento de responsables de la comisión de hechos terroristas;

4. Desarrolla actividades encaminadas a privar a la organización delictiva de medios y recursos predispuestos para contribuir a su criminal actividad, o de los beneficios obtenidos con ella; o

5. Contribuye de forma decisiva a la desarticulación de la asociación terrorista, mediante la comunicación a las autoridades de cualquier información relevante. (Nuevo Proyecto del Código Penal, 2016)

\section{Según la reforma aprobada el viernes 24 de Febrero del 2017, entrando en vigencia el 27 de febrero del mismo año.}

El presente artículo se encuentra reformado en nuestro actual código penal, estableciendo que serán juzgadas ciertas situaciones que han acontecido en el territorio nacional, por disturbios en la población, por el descontrol del orden público con manifestaciones de ciertos partidos políticos, para fomentar el daño de instalaciones públicas y privadas, consistiendo también en el daño a las personas.

\section{DECRETA:}

Articulo 1.- Reformar los artículos 22 y 335; adicionar los artículos 335-A y 335-B, del decreto N.14483, de fecha 23 de agosto de 1983, que contiene el código penal y sus reformas, las cua-les deben leerse de la manera siguiente:

Artículo 335. Delito de Terrorismo. Comete el delito de terrorismo:

Dice Quien realice cualquier acto destinado a causar la muerte o lesiones corporales graves, incendios u otros estragos contra un ciudadano civil o su propiedad o contra cualquier otra persona que participe directamente en hostilidades en una situación de conflicto armado, cuando el propósito de dicho acto o evento por su naturaleza o contexto, sea el de intimidar o causar un estado de terror en la población. 
0, de obligar a un gobierno o una organización internacional al realizar o abstenerse a realizar cualquier acto.

También comete delito de terrorismo...

El responsable del delito de terrorismo será...

Incurre además en dicho delito quien o quienes formen parte de asociaciones ilícitas y desarrollen acciones cuyo propósito sea, mediante la comisión de delitos violentos o amenaza de cometerlos, alterar gravemente la paz pública, aterrorizar o intimidar la población o aparte de ella, para obligarla a realizar un acto o abstenerse de hacerlo.

Artículo 335-A.- Se deben aplicar las penas contempladas en el artículo precedente a quienes fueren integrantes de grupos que causen daños al territorio o a personas forjando fuerza para la seguridad del estado o estabilidad económica del país, se procederá a considerarse como terrorista.

\section{En el Articulo 335 B... Apología e incitación de actos de terrorismo.}

Dice quien públicamente o través de medios de comunicación o difusión destinados al público hiciere apología, enalteciendo o justificación del delito de terrorismo o de quienes hayan participado en sus ejecución o, incitare a otro u otros a cometer terrorismo o el financiamiento de este, debe ser sancionado con una pena de cuatro (4) a ocho (8) años de prisión.

En primer lugar vamos a despejas lo ¿Qué es una apología? Es el discurso que se realiza en defensa o alabanza de algo o alguien. Se trata de expresiones orales, escritas o de otro tipo que se difunden con la intención de brindar apoyo a una persona, una organización o una causa.

Y cuando se refiere a "apología del odio" Que es un discurso que se realiza algo contra alguna persona, institución, que trata de expresiones escritas, con la intención de causar que la persona atacada pretenda tener una causa, y así desorganizar el estatus del mismo.

Comentario: La apología del odio se refiere a daños, en realidad en Honduras sea creado estos casos podemos decir de manera diaria, esto pase más en el sector público y político en el cual entre los mismos funcionarios se agreden y hasta han llegado al punto de faltarse el respeto y golpearse, además esto quiere decir que hay líderes que fomentan el odio Hondureño a muchos ciuda-danos creando controversia y disturbios en el orden público del país. Decreto No. 6-2017. (Reformar y Adicionar Artículos al Código Penal, 2017)

En lo cual el artículo 2, con sus reformas en numeral B literal B del Decreto Legislativo No. 241-2010 publicado en el Diario Oficial la Gaceta, el 18 de Noviembre de 2010, que contiene la ley contra el financiamiento del terrorismo el cual se lee de la siguiente manera.

Consiste las definiciones para los efectos de esta ley se entenderá lo siguiente:

1. Actividades y Profesionales

2. Activos o fondos

3. Actos terroristas 

4. Clientes
5. Comiso
6. Comisión
7. Convenciones
8. Instituciones
9. Instrumentos
10. Medida

En lo cual consiste en que persona o en que hechos o actos delictivos se puede cometer lo que es delito de terrorismo en cual la lista de definiciones es muy amplia y abarca más de 25 definiciones en cual también en la Ley de financiamiento del terrorismo fue reformada el mismo día que el artículo 335 del Vier-nes 24 de febrero.

Comentario: Las expresiones de odio o el discurso destinado a intimidar, oprimir o incitar al odio o la violencia contra una persona o grupo en base a su raza, religión, nacionalidad, género, orientación sexual, discapacidad u otra característica grupal, no conoce fronteras de tiempo ni espacio.

Se han empleado expresiones de odio para acosar, perseguir o justificar privaciones de los derechos humanos y, en su máximo extremo, para racionalizar el asesinato.

Con el crecimiento de Internet y de otros me-dios modernos que facilitan la divulgación de expresiones de odio, muchos gobiernos y organismos intergubernamentales han tratado de limitar los efectos perniciosos de este tipo de discurso. Sin embargo, estos esfuerzos chocan naturalmente con el derecho a la libertad de expresión garantizado por numerosos tratados, constituciones nacionales y legislaciones internas.

\section{Convención Americana sobre Derechos Humanos.}

En Américas, el artículo 13 de la Convención Americana sobre Derechos Humanos prevé un amplio grado de libertad de expresión al garantizar el derecho a "buscar, recibir y difundir informaciones e ideas de toda índole". El artículo 13 protege esta libertad al proscribir la censura previa y las restricciones indirectas, y permitir únicamente la posterior imposición de responsabilidad en un conjunto pequeño y definido de excepciones, como las destinadas a proteger la seguridad nacional, el orden público y los derechos y la reputación de los demás.

Comentario: La Comisión Interamericana de Derechos Humanos y la Corte Interamericana de Derechos Humanos han mejorado la definición de esta libertad a través de su jurisprudencia en las décadas recientes.

Es amplio manto de la libertad de expresión, sin embargo, no es absoluto. La Convención Americana al igual que numerosos pactos internacionales y regionales- declara que las expresiones de odio quedan al margen de la protección del artículo 13 y exige que los Es-tados Partes proscriban esta forma de expresión. En el párrafo 5 del artículo 13 se establece:

Estará prohibida por la ley toda propaganda en favor de la guerra y toda apología del odio nacional, racial o religioso que constituyan incitaciones a la violencia o cualquier otra acción ilegal similar contra cualquier persona o grupo de personas, por ningún motivo, inclusive los de raza, color, religión, idioma u origen nacional. 
El Relator Especial para la Libertad de Expresión de la Comisión Interamericana de Derechos Humanos de la Organización de los Estados Americanos también ha formulado declaraciones en esta esfera de la expresión. En una declaración conjunta con el Relator Especial de las Naciones Unidas.

Sobre la Libertad de Opinión y Expresión y el Representante sobre la Libertad de los Me-dios de la Organización para la Seguridad y la Cooperación en Europa (OSCE), el Relator Especial reconoció que las expresiones que incitan o fomentan "el racismo, la discriminación, la xenofobia y la intolerancia" son perniciosas y que los delitos de lesa humanidad con frecuencia van acompañados o precedi-dos de esta forma de expresión.

En la Declaración Conjunta se señala que las medidas que rigen las expresiones de odio, habida cuenta de su interferencia con la libertad de expresión, deben estar "previstas por ley, servir un fin legítimo establecido en el derecho internacional y ser necesarias para alcanzar ese fin”. Se agrega que las expresiones de odio, de acuerdo con el derecho internacional y regional.

Tienen que encuadrarse, como mínimo, en los siguientes parámetros:

1. Nadie debe ser penado por decir la verdad;

2. Nadie debe ser penado por divulgar expresiones de odio a menos que se demuestre que las divulga con la intención de incitar a la discriminación, la hostilidad o la violencia;

3. Debe respetarse el derecho de los periodistas a decidir sobre la mejor forma de transmitir información y comunicar ideas al público, en particular cuando informan sobre racismo e intolerancia

4. Nadie debe ser sometido a censura previa, y

5. Toda imposición de sanciones por la justicia debe estar en estricta conformidad con el principio de la proporcionalidad

De otro, todas las medidas deben ser respetuosas del derecho a la libertad de expresión, de conformidad con el artículo 13 de la Convención Americana.

\section{Terrorismo}

El terrorismo es un acto ilegal de violencia que resulta muy particular cuando se compara con todos los demás, pues no produce un daño objetivo, sino que busca sembrar un temor descomedido en las potenciales víctimas.

Por otra parte, la estrategia de propaganda es otra de sus armas fundamentales, ya que con todo tipo de contenido, como imágenes y vídeos muy violentos de decapitaciones, ahorcamientos y crucifixiones, logran una comunicación eficaz en el mundo entero. En adición a lo anterior, todas sus producciones son subtituladas en inglés y difundidas a través de su página web y redes sociales, lo que aumenta su alcance.

La evaluación que hacemos frente al peligro que siembran los terroristas se ve influenciada por tres situaciones principalmente: primero, por nuestra historia ancestral, es decir, por todo aquello que hemos aprendido a temer desde la evolución, como la muerte, la soledad o la oscuridad. Segundo, por lo que podemos controlar: generalmente pensamos que todo aquello sobre lo que tenemos control no nos hará daño, y como el terrorismo se fundamenta en sacarnos de la zona de confort, logra engendrar el pánico. (Espinosa \& Molinares, 2015) 
Y tercero, por aquello de lo que disponemos inmediatamente: todas las imágenes que nos muestran los medios de comunicación sobre los actos terroristas, los vídeos que existen en redes sociales sobre decapitaciones y las amenazas que envían constantemente a los gobiernos, entre otros. (S., 2011)

\section{COMENNTARIOS DE CONGRESISTASM, RESUMEN}

¿Qué es el terrorismo?

Siempre ha habido dificultades para definirlo y este problema sigue siendo en nuestros días un obstáculo para llegar a una convención internacional general contra el terrorismo, como veremos más adelante. Es difícil distinguirlo de otros crímenes como la violencia o el asesinato político, la guerrilla o el anarquismo. Por ello, la comunidad internacional parece inclinada a condenar y sancionar los actos terroristas, aún sin alcanzar una definición generalmente aceptada del crimen mismo.

Hay definiciones muy amplias y otras más restrictivas. Sólo en términos muy generales, diremos que muchos intentos de definirlo dan importancia al objetivo del terrorista diciendo que es la táctica de utilizar un acto o una amenaza de violencia contra individuos o grupos para cambiar el resultado de algún proceso político. Otros definen al acto terrorista por su especie, como aquél en que se utiliza la violencia en contra de las personas o los bienes indiscriminadamente con el resultado de producir miedo o pánico.

Hay otras ocasiones, en las que el motivo parece ser solamente el odio o la venganza. El acto te-rrorista que no tiene objetivo es simple locura y también los hay. En el acto terrorista es común el desprecio por la vida humana y por el sufrimiento que dicho acto puede causar, los que se consideran poco significativos frente a la trascendencia real o imaginaria del objetivo buscado por el terrorista.

\section{"No podemos permitir la apología e incitación" al terrorismo, dice Óscar Álvarez sobre Artículo 335-B y Articulo 335 A, del actual Código Penal.}

El diputado Óscar Álvarez Guerrero. De la bancada nacionalista argumenta lo siguiente:

Según su criterio de la apología del odio.

Luego de la polémica reforma al Artículo 335-B del Código Penal, que para muchos atenta contra la libertad de expresión en Honduras, el diputado Óscar Álvarez justificó la misma al expresar que "si nosotros estamos tratando de frenar el terrorismo en nuestro país no podemos permitir que personas vengan y hagan apología e incitación a que se sigan quemando buses".

- El congresista dijo que la adición del párrafo al Artículo 335 se hizo ante la presencia de los medios de comunicación y otras bancadas.

El jefe de bancada del Partido Nacional, Óscar Álvarez, dijo que en los dos días que se discutieron las reformas penales estuvieron presentes todos los medios de comunicación en la Cámara Legislativa.

Continuó que "ellos, la oposición, no están en misa, no está en clase, algunos están presentes, otros está haciendo bulla oponiéndose a todo y no se dan cuenta lo que se está discutiendo, entonces se aprobó de conformidad con la ley y de conformidad con el reglamento del Congreso". 
Álvarez negó que el Artículo 335-B sea una ley mordaza. "Su servidor jamás va a poner en peligro la libertad de expresión, pero si nos vamos a la Convención Americana de Derechos Humanos de la Organización de Estados Americanos, conocida como el pacto de San José firmada el 22 de noviembre de 1969, en el artículo 13 habla de la libertad de pensamiento y de exprese Congreso Nacional aprobó anoche los primeros artículos del Código Penal y Código Procesal Penal, en los cuales se tipifica el delito de terrorismo a todo acto vandálico que cause terror.

Contrario a otras sesiones, la de ayer comenzó a las 3:00 pm como estaba convocada.

Pero no estaban la mayoría de los diputados.

Para el caso, la mayoría de diputados de Libre, al iniciarse la discusión, estaban en la protesta que se dio a inmediaciones del Congreso Nacional.

En el debate hubo momentos álgidos sobre todo cuando el presidente del Congreso Nacional, Mauricio Oliva, le quitó la palabra al diputado de Libre, Bartolo Fuentes, quien recibió la solidaridad de sus compañeros, quienes sacaron de sus bolsillos unos silbatos, los que hicieron sonar, provocando con ello que se suspendiera la sesión en el momento que ya se habían aprobado los primeros cuatro artículos de las reformas penales, con 54 votos a favor y 34 en contaron". (Digi-tal, 2017)

Hay muchos comentarios y disturbios en la cámara de legisladores debido a que la bancada nacionalista aprobó esta reforma con la falta de muchos diputados de la bancada liberal y libre no fue suficiente para impedir esa situación, debido que el día que se aprobó dicha reforma hubieron muchos disturbios en el país, por lo cual la po-blación está en desacuerdo porque hicieron todo lo contrario que estaba en la reforma y comenzaron a hacer daños a establecimientos y tomas de la UNAH.

Los diputados del Partido Liberal, prefirieron mantenerse al margen y no presentarse al congreso ese día, para evitar cualquier controversia con los otros partidos políticos, la Bancada del Partido Libertad y Refundación hicieron una declaración muy intimidante a los diputados del Partido Liberal de Honduras.

Para odiar no necesitamos mayores razonamientos.

Comentario: Se puede odiar a cualquier persona sin conocerla. Podemos odiar una manera de pensar que de inmediato nos resulta repulsiva o un razonamiento que va contra nuestros valores y principios. Ante la triste verdad de que todos los seres humanos somos distintos y de que las ideas entre una persona y otra son tan diversas, no queda otro remedio que amar lo que se conoce y odiar lo desconocido.

Decir la verdad con "odio" en Honduras será un acto de terrorismo

Aprovechando un "desorientamiento" de los diputados cuando se aprobaban en el Congreso Nacional las reformas penales donde se ha creado la figura del terrorismo, y que castiga con duras penas a quienes alteren gravemente la paz pública, el presidente de la bancada del Partido Nacional, Oscar Álvarez, logró hacer un agregado en uno de los artículos, donde expone a los periodistas a ser acusados de "terroristas".

No estaba presente la bancada del partido liberal, en lo cual eso dio muchas expectativas.

Mediante una reforma al artículo 335B del Código Penal, se estableció que incurre en apología del odio e incitación de actos de terrorismo, quien "públicamente o través de medios de comunicación o difusión 
destinados al público hiciere apología, enaltecimiento o justificación del terrorismo o de quienes hayan participado en su ejecución, o incitare a otro u otros a cometer terrorismo o, financiamiento de éste, será sancionado con pena de cuatro a ocho años de prisión".

Según Álvarez, algunos medios de comunicación y periodistas de Honduras promueven la apología del odio al exagerar con datos o noticias sobre diferentes aspectos del accionar público.

La petición del también ex secretario de Seguridad es muy amplia y subjetiva por lo que cualquier periodista o comunicador social estará a expensas de ser enjuiciado sin fundamento alguno.

El diputado por el opositor Partido Libertad y Refundación (Libre), Jari Dixon Herrera, dijo que la nueva figura es para impulsar miedo a aquellos periodistas independientes que auditan al gobierno.

Asimismo, indicó que el actual Código Penal ya establece las penas en contra de quienes fomen-ten la apología del odio, pero ahora se ha particularizado involucrando a los medios de comunicación como autores directos.

Comentario: Hoy en día se habla mucho del odio. Hacia los políticos, hacia los banqueros, hacia los ricos. Todo aquello que sentimos que representa nuestro malestar o que ocasiona nuestros problemas, es susceptible de ser odiado. Pero además algunos lo califican como peligroso y hasta se planea penalizarlo jurídicamente.

Pues puede incitar a delitos más graves. El odio será llamado apología del delito o del odio, si ese sentimiento expresado en los medios sociales termina siendo por casualidad o no, un mecanismo para que se cometa un delito. Y nos conciencian que el odio es malísimo. (Andrés, 2014)

En la medida que sean utilizados medios informáticos para difundir las doctrinas que ensalzan el delito, la apología de delitos se convierte en delito informático, y en este sentido, son cada vez más numerosas las intervenciones frente a páginas Web que promocionan conductas delictivas como las mencionadas.

Con todo, quiero insistir que se trata de un numerus clausus: sólo puede ser castigada como forma de provocación la apología de aquellos delitos para los que el código lo prevé.

La razón de ser de este delito está clara: la liber-tad de expresión no puede amparar la lesión de bienes jurídicos superiores. Cuando la libertad de expresión se convierte en un instrumento al servicio de los que atentan contra la vida y la libertad, debe actuar el derecho penal. (España)

Terrorismo y Educación.

Reflexionar sobre la educación dentro de este nuevo contexto mundial se hace una tarea obligada y necesaria para todos, especialmente para aquellos quienes nos dedicamos a la investigación en esta área. Considero pertinente que en este momento nos preguntemos: ¿cuál será el papel de la educación en este nuevo momento histórico?.

Entendiendo aquí a la educación, como una herramienta usada por los estados para lograr sus fines; fines que a su vez, han sido formulados respondiendo a distintos aspectos, entre los cua-les están evidentemente, las exigencias del orden internacional. Hasta ahora, la tendencia globalizadora había venido influyendo considerablemente en los sistemas educativos de la mayor parte de los países latinoamericanos y del mundo occidental en general. 
Los líderes de los países más poderosos del mundo clamaban por un mundo globalizado. Paradójicamente, esta idea también ha inspirado a los llamados terroristas a crear sus propios "consorcios y multinacionales del terror" dispersándose por el mundo, generando con ello recelo e inseguridad.

Conscientes de los cambios que esto producirá es menester entonces proponer un nuevo debate en educación.

\section{¿Cuál Terrorismo?}

La interrogante que he planteado tiene dos par-tes, una sobre la definición del vocablo terrorismo, y la otra sobre el tipo o los tipos de terroris-mo. Sin embargo, es pertinente antes de desarrollar este punto, hacer mención a la importancia que tiene el contexto internacional en la definición de la educación de un estado. Esto le permitirá al lector entender las razones que me motivan a plantear un debate sobre el binomio terrorismo y educación.

Al elaborar un Proyecto Nacional, diversos as-pectos deben ser observados y analizados para que este tenga, a pesar de su aspecto normativo, un basamento tangible que hable de la realidad de ese país. Un elemento esencial en la formulación de un proyecto es el análisis del lugar estratégico que ocupa el país en el concierto mundial, que a su vez define el papel que debe jugar la educación dentro de ese estado.

Ciertamente la educación en cada uno de estos países no depende solamente de su posición estratégica, sería un atrevimiento limitarla a esto. También determinan sus diferencias los aspectos internos como su historia, tradiciones y valores culturales, así como la disposición política de sus líderes en relación con lo educativo.

Sin embargo, insisto, es necesario comprender cuán vulnerable es la educación frente al contexto internacional, para luego decidir cómo actuar en el mismo. Como ya hice mención anteriormente, los acontecimientos del pasado septiembre en los Estados Unidos, han comenzado a modificar el panorama mundial, generando con ello una nueva polarización del mundo, del que no es posible aún definir quiénes conformarán esos polos y cómo lo harán. Pareciera que el panorama dibuja un nuevo bipolarismo, constituido por los "antiterroristas" y los "terroristas".

Lo importante es que ahora los Estados Unidos han precisado con más detalle a su nuevo enemigo, del que desde el fin de la guerra fría sólo se había hecho un boceto que incluía distin-tos actores. (Sequera, 2001)

\section{RESULTADOS}

Los resultados esperados en esta investigación es que nuestros espectador conozcan y observen la tendencia actual en nuestro país por el delito de terrorismo y que en el entorno de muchos casos que se han presentado en el país, porque muchas personas se han visto afectadas ante la situación en el cual las personas han salido denigradas por una situación a lo que puede ser política, cultural o social.

Que en dado caso se han presentado por situaciones adversas y por conflictos que otras personas crean y hacen que la imagen de esa persona quede ante la sociedad en este caso el pueblo hondureño en mal, tratando de asuntos que a la sociedad le causan molestia y al cual cualquier tipo de persona, puede causarle daños o lesiones debido a que la persona que quiere causar el daño lo hace público. 
Y también lo comunicarón por medios de comunicación masivos, en lo cual es a lo que llamamos la famosa apología del odio, debido a que en lo que anteriormente hemos expuesto es considerado como delito, en cual se tendrá que imponer una pena máxima hasta 8 años de reclusión, en lo cual cómo escritor me comprometí a exponer lo que es la apología y en que delito constituiríamos.

Debido a que ya está siendo penado por la ley, debido que el resultado que esperamos obtener es esclarecer lo que es la apología y que las personas conozcan cuales son las medidas o si es o no perjudicial para el pueblo hondureño, debido a que como escritor es algo factible debido a que esto se consideró como un respaldo de parte del partido que en la actualidad está gobernando al país.

Eso quiere decir que tiene fines políticos, pero si lo aplicamos según los acontecimientos que suceden en nuestro país, esto no solo se dan en políticas, sino que también se da en nuestras comunidades, porque por ciertas ocasionales sean verdaderas o falsas hasta han llegado a quitarle la vida personas, además que hoy en día la política está siendo un rubro que está dando mucho que desear en los medios nacionales e internacionales.

Debido a que según esta situación a descontrola-do y ha hecho que la población hondureña se descontrole, un caso es parecido al de la acusación de una diputada del congreso que debido a las fuertes declaraciones por otros congresistas y demás compañeros de trabajo, se dice que cometió ilícito debido a que vendió las famosas pastillas de harina, lo cual.

La población la repudia y la odia, porque han fo-mentado dicha apología. (Berrios, 2017)

En vez de sancionar esta conducta, que podría colocar en vulnerabilidad el Derecho a la libertad de expresión y el Derecho a la Libertad de Pren-sa, el gobierno se ha sumado a hacer uso del argumento de la "apología del odio" con el fin de estigmatizar a quienes denuncian la corrupción estatal y piden justicia para así impedir la circulación de ideas y opiniones.

Advierte que la apología del odio es uno de los discursos que no está protegido por la Conven-ción Americana de Derechos Humanos y bajo este argumento, el gobierno podría legislar para restringir derechos fundamentales.

El 18 de septiembre, el portal de Casa Presiden-cial (http://www.presidencia.gob.hn/?p=7490), informó que "el presidente Juan Orlando Hernández sentenció, en la ceremonia de ascensos de 89 oficiales de la Policía Nacional, que se equi-vocan quienes pretenden sembrar odio en el país y aseveró que su Gobierno seguirá esforzándose por la paz.

El gobernante puntualizó en su discurso que "hay unos que equivocadamente creen que sembrando odio pueden tener dividendos para su propósito", lo que es "algo equivocado". Agregó que, de parte del Gobierno, "seguiremos empeñados en propiciar un clima de paz y de tranquilidad en el país".

El odio se genera por la impunidad de los gobernantes del país, implicados en el escándalo de corrupción del Instituto Hondureño de Seguridad Social (IHSS).

Considerando que con esta campaña, se ha transferido el incumplimiento estatal a los medios de comunicación, es el gobierno el que tiene la obligación de castigar a los delincuentes de cuello blanco. 
Con el discurso de sus funcionarios, el gobierno ha desviado la atención para manipular a la población y hacerle creer, mediante la confrontación entre los medios, que los responsables de la violencia son los periodistas, ciudadanos y quienes tienen derecho a la libertad de expresión.

Este mecanismo indirecto de censura, encaminado a impedir la comunicación y la circulación de ideas y opiniones, atenta contra la democracia y coloca en vulnerabilidad el Derecho a la Libertad de Expresión, uno de los fundamentos de la democracia.

La Declaración Conjunta sobre Difamación de Religiones y Sobre Legislación Anti-Terrorista y AntiExtremista de los Mecanismos Internacionales para la Promoción de la Libertad de Expresión cita que "subrayando que la mejor manera de afrontar la existencia de prejuicios sociales es a través de un dialogo abierto que exponga el daño causado por tales prejuicios y combata los estereotipos negativos, aunque al mismo tiempo sea apropiado prohibir la incitación al odio, la discriminación o la violencia".

"Las restricciones de la libertad de expresión para prevenir la intolerancia deben limitarse a la apología del odio nacional, racial o religioso que constituya incitación a la discriminación, la hostilidad o la violencia"

De conformidad con la Convención Americana, todos los seres humanos pueden disfrutar y ejercer todos los derechos en igualdad, sin dis-criminación alguna por motivos de raza, color, sexo, idioma, religión, opiniones políticas o de cualquier otra índole, origen nacional o social, posición econó-mica, nacimiento o cualquier otra condición social. Según lo ha reconocido la Corte Interamericana, dentro de la prohibición de discriminación por orientación sexual.

\section{Actualidad del Terrorismo}

Cualquier debate acerca del concepto y fenó-meno del terrorismo tiene garantizada la aparición de controversia, emociones, imprecisiones y confusión, hasta el punto de que, tal y como ha dicho la experta Louise Richardson, lo único seguro sobre el terrorismo es que se trata de un término de connotación peyorativa. Que el uso de una palabra te enseñe su significado, escribió Wittgenstein en un aforismo que, dada esta situación, parece especialmente aplicable a los términos terrorista y terrorismo.

La utilización del término terrorismo para señalar diversos tipos de comportamiento, o de conducta punible, ya no se reserva a la justa proporción del mismo, el profundo daño ocasionado en la década pasada por quienes insistieron en perpetrar actos encaminados a lesionar a escala planetaria terminaron imponiendo su deseo de atemorizar a través de sus actos a la mayor cantidad de población posible a nivel mundial.

La importancia de que un organismo multilateral, en este caso, la ONU, describa al terrorismo como tipo penal universal, debiendo ser adoptado por los países que tienen representación en esta organización, es vital pues evitaría la ambigüedad que genera el vacío en favor de los terroristas, así como imprecisiones en algunos que lo han tipificado, pues les permite que en ciertos países no sean vistos como tales y gocen de libertad, e inclusive hasta de protección por parte de gobiernos cuyos estados tienen un asiento en la ONU.

\section{Tipos de Terrorismo}

En este apartado se analiza cómo el terrorismo tiene algunas fronteras que limitan la ejecución de sus actos, fronteras rígidas o flexibles. 
a. Local o regional

Este tipo de terrorismo se originó durante la Gue-rra Fría y la ejecución de decisiones de carácter político y estratégico estableció la materialización del mismo. Es un terrorismo concentrado en un lugar específico y con un objetivo (enemigo) claramente fijado, de tal forma que sus acciones van dirigido.

Sólo a la población de un espacio geográfico concreto, blanco predeterminado de sus acciones terroristas. Continuando, este terrorismo se concentra en objetivos limitados en el espacio, y específicos, actuando según las necesidades socio políticas del momento.

b. Global o internacional

El terrorista, entonces, siente que le ha fallado a su país y a sus connacionales, pues no está allí para sufrir con ellos aquello que denominan invasión occidental, por lo que desarrolla el odio ha-cia el país de acogida, al que ve como culpable de eso que él mismo denomina traición. Este sentimiento está alentado por discursos de animadversión hacia occidente y principalmente está ocurriendo en las mezquitas de los países europeos, lo cual hace que la amenaza adquiera connotaciones globales.

La mayoría de los jóvenes radicales islamistas ha abrazado el terrorismo en países occidentales. Este otro tipo de terrorismo está orientado a afec-tar la mayor cantidad de población posible, no se limita a una región en particular, sus propósitos, la dimensión de sus actos, así como el tamaño de la organización trascienden el terrorismo regional o local.

Su público es todo público, pues su accionar se dirige a aterrorizar a la población global, de tal forma que podríamos decir que no tiene fronteras que limiten su actuación. Lo anterior hace que la amenaza terrorista sea proporcional a la zozobra y el pánico que se busca como objetivo, el cual casi siempre es selectivo, salvo error propio. El terrorismo global es simbólico, por ello buscan lugares emblemáticos contra los cuales atentar, de tal forma que si consigue penetrarlos, demostrarán la vulnerabilidad de la seguridad nacional del país escogido como objeto del atentado.

\section{Clasificación de Terrorismo.}

Destacamos la siguiente clasificación a modo de síntesis, desde cuatro planteamientos: origen, función, efectos y naturaleza.

a. Origen: corresponde a los objetivos de cada uno, es decir, al plan que se persigue con los actos terroristas. Por ejemplo, el terrorismo cuyo propósito es producir la modificación política de un país, como puede ser la del gobierno, del sis-tema y con ello el cambio de vida de la sociedad, generalmente persigue más de un objetivo dentro del ámbito político, lo cual hace que sus demandas sean tan complejas como poco realizables.

b. Por su función: A partir de ella, el objetivo es mucho más claro y más específico. El separatismo, una vez que realiza el terrorismo, suele terminar. Así, el ira, al conseguir su objetivo, cesó en sus actividades terroristas, podríamos señalar que esta práctica se utilizó como mecanismo de solución del conflicto, pues llegados a un acuerdo, la acción terrorista termina en su función. 
Este tipo de terrorismo pocas veces declina en su objetivo hasta antes de conseguirlo. Ubicado, históricamente en Europa.

c. Por sus efectos: Los grupos terroristas tienen la finalidad de mantener durante un tiempo el terror en la sociedad, como mecanismo generador de miedo, con el que la población deberá, según ellos, convivir durante el mayor tiempo posible, dado que sus requerimientos no son específicos, sino generales.

No tienen un propósito único que perseguir, podríamos afirmar que el miedo lo es, pero éste no es una reivindicación que se pueda erigir como objetivo priori-tario de un grupo terrorista de otra categoría como las anteriores.

d. Por su naturaleza: El terrorismo suele, la mayoría de las ocasiones, tener su causa en la religión, y fundamentándose en ella se cometen actos terroristas. Observamos cómo los terroristas islámicos ejecutan sus ataques en nombre de Alá, se inmolan en su nombre y materializan así aquella premisa de morir matando. Pero no sólo los anteriores se sustentan en la religión como objeto último de su causa, en los Balcanes, bajo el mismo postulado, se llevó a cabo una mal llamada limpieza étnica que aniquiló miles de vidas.

En efecto, en nuestra historia contempo-ránea han sido los Balcanes la expresión máxima de la utilización de la religión como método terrorista, puesto que ni si-quiera Al Queda la tuvo, la suya fue ante todo política. En todo caso dentro del Is-lam sí podemos hablar de conflictos de religión, por ejemplo, la usual confronta-ción entre Chiíes y Sunníes está imbuida de todo el carácter religioso posible, Sadam Hussein ejecutó con gas mostaza a más de 5, 000 kurdos en Irak, él era un musulmán Suni y este acto fue de lo más explícito del terrorismo religioso conocido en nuestra historia contemporánea. (Morales, 2015)

\section{CONCLUSIONES}

1. Concluyendo de lo siguiente: La cámara de legisladores hicieron la reforma por la siguiente razón, en las cuales hay interés poblacional e interés político de parte del Partido Nacional, en lo cual en los últimos años se ha demostrado que muchos aspirantes y funcionarios ya electos han fomentado odio sobre una persona a otra, creando que el pueblo pierda sus estabilidad y haya disturbios y en los últimos 3 años en cual ha tenido el poder el Mandatario Juan Orlando Hernández.

2. Muchos funcionarios han tratado y al punto de lograr que el pueblo pierda la estabilidad, debido a que crean el odio sobre él públicamente, y ha tenido que soportar agresiones y humillaciones muchas veces, la apología del odio considero que fue creada para detener lo que es el abuso de funcionarios de la cámara de legisladores contra muchos aspirantes y diputados del mismo partido nacional. Debido a que ellos son los más acusados por el pueblo y funcionarios del mismo gremio, entonces el articulo 335 B, fue implementado para DETENER todas esas agresiones y conservar la estabilidad nacional, ahora existen requisitos en los cuales si algún funcionario o cualquier persona está en contra de la otra y lo hace público por el medio de comunicación masivos. 
3. La apología como es la exposición, ante una concurrencia de personas o por cualquier medio de difusión, de ideas o doctrinas que ensalcen el crimen o enaltezcan a su autor.

4. La apología sólo será delictiva como for-ma de provocación y si por su naturaleza y circunstancias constituye una incitación directa a cometer un delito. En este sentido, el código penal castiga la apología de los siguientes delitos: homicidio y asesinato, lesiones, detenciones ilegales y secuestros, exhibicionismo y provocación sexual, robo, extorsión, estafa o apropiación indebida, receptación y otras conductas afines, cultivo y tráfico de drogas, rebelión militar, delitos contra la corona, asociación ilícita, sedición, atentados, terrorismo, y genocidio.

5. Fomentando odio hacia las demás personas será sancionado con reclusión. La motivación del terrorismo parece ser, pues, alcanzar un objetivo o fin, generalmente político y que puede ser hasta altruista o noble, pero por la vía condenable de eliminar o intimidar a quienes se oponen a dicho fin u objetivo.

6. El odio es una muy cómoda impotencia. Hagamos este ejercicio, la próxima vez que encontremos otro nuevo criminal en las fotos de prensa, odiémoslo con todas nuestras fuerzas, enviémosle todo nuestro desprecio y luego esperemos a ver qué pasa. El criminal se irá, como todo, pero el odio siempre permanecerá.

7. La tendencia actual, sobre las reglas de interpretación en las reformas penales es muy explícita porque en el artículo se demuestra que hay diversas formas de entender lo que es odio, lo que es apología y mucho menos lo que es terrorismo, el problema del pueblo hondureño es que no le gusta leer y no se informa, pero la norma está muy clara con su precepto y pena y ya el que incurra en ese delito en dado caso que no sea derogado no puede alegar desconocimiento de la ley.

8. La convención de Derechos humanos, habla de la igualdad y que no podemos practicar el odio hacia otras personas, debido a que incitar el odio podría ser, a personas que no consideramos agradables o a personas de distinta definición sexual, política y económicas, debido a que esas personas son las que más su-fren por odio de parte de muchos pueblos.

\section{RECOMENDACIONES}

1. Se recomienda a la cámara de legislado-res que para poder aprobar esas dichas reformas tienen que estar presentes todas las bancadas, debido a que no lo tienen que hacer por resguardo político sino porque el pueblo salga adelante, teniendo en cuenta la participación de todas las bancadas y aprobarlo de una manera correcta.

2. Que no busquen un bienestar político sino ayudar al pueblo sobre lo que es realmente el terrorismo, debido a que no es tanto por seguridad mutua de la bancada del partido nacional, si no por ayudar al pueblo a combatir el terrorismo y a disminuir en el pueblo el odio hacia políticos 
3. Nada enciende tanto rechazo en nosotros como aquello que nos rechaza. Así que el fulgor del odio también necesita de más odio para que todo arda. Si un sentimiento es correspondido, crece, y si crece, se propaga. La Historia, leída y estudiada sin profundidad, hace que el odio traspase una y otra generación como si fuesen papel calco. Fomentemos el respeto hacia los demás y tratemos la convivencia y la paz al pueblo hondureño.

4. Se recomienda al presidente de la repu-blica que apoye realizando una campaña que no afecte la crisis política en el país, incitando al pueblo a que sea tolerante y comprensivo hacia diversas situaciones que pasan día a día, e impulsar a que ya no haya más odio.

5. Se recomienda a las bancadas de diver-sos partidos políticos, que cuando se traten de reuniones ordinarios en la cámara de legislación, se presenten debido a que son situaciones que no serán de problemas o insultos, si no problemas que afectan a la población hondureña.

6. Se recomienda derogar el Artículo $335 \mathrm{~B}$, debido a que considero que se está violentando la libertad de expresión a los medios de comunicación, debido a que ya no se puede reprimir al pueblo de las situaciones que están pasando hoy en día.

7. Se recomienda que para el delito de la apología del odio, se considere como una falta, en lo cual no impida la libertad de expresión, debido a que es una garantía constitucional a que nos expresemos libremente.

8. Se recomienda a la policía Nacional, que se oriente, debido a que se encontró un hallazgo que ellos están poco instruidos a lo que es el terrorismo y como saber si es odio y apología.

9. Se recomienda a la corte suprema de justicia, que proponga un proyecto, para lo que se deberá tomar como terrorismo interno y externo dentro del país, debido a que ellos son los que más conocen esos tipos de casos y además con asesoramiento de cortes internacionales para poder ejemplificar y condenar correctamente lo que es el delito de terrorismo y apología del odio, sin privar de la libre expresión a los medios de comunicación, y al pueblo en general, dejando espacios para poder comunicar y explicar las situaciones que ocurren en nuestro país.

\section{NOTA}

Este artículo puede servir para desglosar lo que lo que significa la apología del odio, puede ser usado con el visto bueno, que en dado caso los coautores Carlos Francisco Padilla y la Abogada. Jenny Mabel Díaz, y de esta forma lo pueden fomentar para seguir desarrollando las Ciencias Jurídicas y su interpretación de la norma. 


\section{BIBLIOGRAFÍA}

- Código Penal “Decreto 144-83”. (1984). Teguci-galpa, M.D.C, Honduras, C.A.

- Decreto No. 6-2017 (Reformar y Adicionar Artículos al Código Penal). (27 de Febrero de 2017). La Gaceta, Diario Oficial de la República de Honduras, pág. 18.

- $\quad$ Digital, P. (23 de Febrero de 2017). Apología Del Odio. Proceso Digital HN, pág. 2.

- Nuevo Proyecto del Código Penal. (2016). Te-gucigalpa, M.D.C, Honduras.

- $\quad$ Andrés, C. D. (17 de Mayo de 2014). LA APOLOGÍA DEL ODIO. pág. 3.

- Berrios, L. (23 de Febrero de 2017). Decir una verdad con "odio" en Honduras será un acto de terrorismo. ONCE NOTICIAS.

- $\quad$ España, C. d. (s.f.). Código Penal de España. Madrid.

- Espinosa, J. M., \& Molinares, N. Q. (2015). Lo que nos aterroriza del terrorismo. Psicología desde el Caribe, 32.

- $\quad$ Morales, T. G. (2015). El Terrorismo y Nuevas Formas de Terrorismo. Espacios Públicos, 35.

- $\quad$ S., P. (2011). The Better Angels of Our Nature. New York: Viking, pág. 4.

- Sequera, N. (2001). Terrorismo y educación. Educere, 15. 